J. Lake Sci. (湖泊科学), 2014, 26(2): 221-227

http: //www. jlakes. org. E-mail : jlakes@niglas.ac.cn

(C) 2014 by Journal of Lake Sciences

\title{
乌梁素海水体录的分布特征及污染风险评估"
}

\author{
赵胜男 ${ }^{1}$, 史小红 ${ }^{1 * *}$, 李畅游 ${ }^{1}$, 张汉蒙 $^{2}$, 付绪金 ${ }^{1}$, 吴 用 $^{1}$, 石艳秋 ${ }^{3}$ \\ (1: 内蒙古农业大学水利与土木建筑工程学院, 呼和浩特 010018) \\ ( 2 : 内蒙古水利与水电勘测设计院, 呼和浩特 010020$)$ \\ (3: 扎兰屯市水资源管理站,呼伦贝尔 162650$)$
}

摘 要: 于 2011 年 1 月采集乌梁素海表层水样,对湖水中重金属 $\mathrm{Hg}$ 含量进行分析. 结合 $\mathrm{Hg}$ 的空间分布特征,利用单因 子指数综合污染评价指数与健康风险评价模型对 $\mathrm{Hg}$ 污染程度与风险进行评估. 结果表明, 乌梁素海表层水体中 $\mathrm{Hg}$ 的平 均浓度为 $1.04 \mu \mathrm{g} / \mathrm{L}$, 所有监测点 $\mathrm{Hg}$ 的含量都超出地表水 III类标准和国家渔业用水标准, $50 \%$ 的监测点超出了地表水 $\mathrm{V}$ 类标准. 水体中 $\mathrm{Hg}$ 的分布模式与流域排污口位置、入湖口及水动力条件有一定关系, 高值区域分布在入湖口相对集中的 西北与东北部, 湖泊南部与出口处的含量相对较低, 处于中等水平. 乌梁素海湖水中 $\mathrm{Hg}$ 的非致癌性污染物所致的健康危 害风险度介于 $0.75 \times 10^{-9} \sim 2.15 \times 10^{-9} \mathrm{a}^{-1}$ 之间, $\mathrm{Hg}$ 所致的健康危害风险度的贡献率在 $71.43 \% \sim 92.44 \%$ 之间, 表明 $\mathrm{Hg}$ 污染水平与健康风险都较高,应该给予特别关注.

关键词: 乌梁素海;重金属;永;健康风险评价;空间分布特征

\section{Distribution characteristics of mercury and pollution risk assessment in the water of Lake Ulansuhai}

ZHAO Shengnan ${ }^{1}$, SHI Xiaohong ${ }^{1}$, LI Changyou ${ }^{1}$, ZHANG Hanmeng ${ }^{2}$, FU Xujin ${ }^{1}$, WU Yong ${ }^{1} \&$ SHI Yanqiu $^{3}$

(1: College of Water Conservancy and Civil Engineering, Inner Mongolia Agricultural University, Huhhot 010018, P. R. China)

(2: Inner Mongolia Water Conservancy and Hydropower Survey and Design Institute, Huhhot 010020, P. R. China)

(3: The Zhalantun Water Resource Management Station, Hulunbuir 162650, P. R. China)

Abstract: To understand the heavy metal mercury levels in the surface water of Lake Ulansuhai, samples were collected in January 2011. The total mercury concentration was analyzed. Distribution characteristics, pollution levels and health risk assessment were revealed by GIS, Pollution Evaluation Index and Health Risk Assessment Model. The average mercury concentrations in surface lake water were $1.04 \mu \mathrm{g} / \mathrm{L}$, indicating a relatively high content of mercury. All sampling contents were beyond the first surface water standards and national fisheries standards, and 50\% samples were beyond the fourth surface water standards. The high mercury concentrations at the inlet of the lake, while the low concentrations at the outlet of the lake. Considering the health risk caused by non-carcinogen in the water, the risk levels ranged from $0.75 \times 10^{-9}$ to $2.15 \times 10^{-9} \mathrm{a}^{-1}$. The contribution rate of mercury is $71.43 \%-92.44 \%$. The mercury pollution and risk is high and should pay more attention on that.

Keywords: Lake Ulansuhai; heavy metal; $\mathrm{Hg}$; health risk assessment; distribution characteristic

永 $(\mathrm{Hg})$ 是一种毒性极强的元素,其污染具有持久性、易迁移性、高度生物富集性、强毒性等特性,并且环 境中任何形式的 $\mathrm{Hg}$ 均可在一定条件下转化为剧毒的甲基录, 对人体健康造成极大的危害 ${ }^{[14]}$. 同时, $\mathrm{Hg}$ 具 有长程跨界污染的属性,已被联合国环境规划署列为全球性污染物, 是除了温室气体外唯一对全球范围产 生影响的化学物质,已成为全球广泛关注的环境污染物之一, 因此环境中 $\mathrm{Hg}$ 污染研究一直是世界关注的热 点之一 ${ }^{[5]}$. 目前我国在湖泊 $\mathrm{Hg}$ 污染研究方面已经开展了一些工作, 集中于南方湖泊, 主要分析湖泊水体中

* 国家自然科学基金项目 $(5133902,51169011,51169017,51069007,51269107)$ 、水利部公益性行业科研专项项目 (201001039)、国际合作项目 (2011DFA90710) 和校级创新团队项目联合资助. 2013-03-30 收稿;2013-08-12 收 修改稿. 赵胜男(1986 ), 女, 博士研究生; E-mail:zhaoshengnan2005@163.com.

** 通信作者;E-mail: imaushixiaohong@163.com. 
$\mathrm{Hg}$ 的形态、沉积物中 $\mathrm{Hg}$ 污染状态、空间分布特征、形态特征、大气沉降对湖泊 $\mathrm{Hg}$ 的贡献以及湖泊环境对 $\mathrm{Hg}$ 形态分布特征的影响等方面 ${ }^{[6-10]}$. 需要注意的是, 这些研究均是关于非寒旱区的南方湖泊, 针对一般外界 环境条件下的 $\mathrm{Hg}$ 污染问题, 而目前针对寒旱区湖泊 $\mathrm{Hg}$ 污染研究开展的工作十分有限 ${ }^{[11]}$. 水体非点源录的 输人可以由人为活动如农田耕作等引起, 且对于录的输人贡献较大 ${ }^{[6]}$. 乌梁素海流域地处中国北方寒旱区, 属于典型灌区湖泊, 主要污染源来自于流域内的农业面源污染, 化肥流失所携带着 $\mathrm{Hg}$ 的流人占湖泊 $\mathrm{Hg}$ 来 源的较大部分. 流域内矿产资源丰富, 主要包括铜、铅、锌、镉等, 每年大约有 $2 \times 10^{8} \mathrm{~m}^{3[12]}$ 的工业废水、生活污 水排人也会造成乌梁素海水环境 $\mathrm{Hg}$ 的富集与污染. 目前, 乌梁素海的研究主要集中于湖泊富营养化、有机 化污染、沼泽化以及生态健康 ${ }^{[13-16]}$. 关于重金属 $\mathrm{Hg}$ 的研究集中于湖泊沉积物方面, 乌梁素海沉积物中 $\mathrm{Hg}$ 的 含量在大部分采样点超标, 均值为 $0.151 \mathrm{mg} / \mathrm{kg}$, 远大于背景值 $0.028 \mathrm{mg} / \mathrm{kg}^{[17]}$, 其生态风险远远大于其它金 属 ${ }^{[18]}$. 表层沉积物中 $\mathrm{Hg}$ 在乌梁素海最南端形成了局部高值区, 在人湖口区域浓度也较高, 具有南北高、中 间低的变异特征 ${ }^{[19-20]}$; 沉积物中 $\mathrm{Hg}$ 的主要存在形态为有机物和硫化物的结合态 ${ }^{[17]}$. $\mathrm{Hg}$ 可通过水-沉积物界 面间的交换作用进人水相而造成二次污染. 基于对乌梁素海沉积物 $\mathrm{Hg}$ 的研究可知,乌梁素海面临潜在 $\mathrm{Hg}$ 污染风险, 因此, 对水环境中的 $\mathrm{Hg}$ 进行研究势在必行. 此外, 乌梁素海是内蒙古自治区的主要渔业基地, 每 年产鱼量约 700 多万吨 ${ }^{[21]}$, 其湖水终将退水黄河, 每年在枯水期向黄河补水近 $2 \times 10^{8} \mathrm{~m}^{3[12]}, \mathrm{Hg}$ 的特殊物理 化学性质和强毒性会影响湖区渔业与黄河水体安全 ${ }^{[21]}$. 基于乌梁素海的生态功能定位、地区特殊性及 $\mathrm{Hg}$ 污染的危险性, 研究乌梁素海水环境中 $\mathrm{Hg}$ 的含量、分布特征、健康风险评估具有重大意义.

本文以乌梁素海为主要研究对象, 研究了湖泊表层水体基本理化特征以及水中 $\mathrm{Hg}$ 含量及分布特征, 利 用单因子指数法对湖区内 $\mathrm{Hg}$ 进行污染评估, 并运用水环境健康风险评价模型对整个湖区水体中 $\mathrm{Hg}$ 进行健 康风险评估.

\section{1 材料与方法}

\section{1 研究区概况}

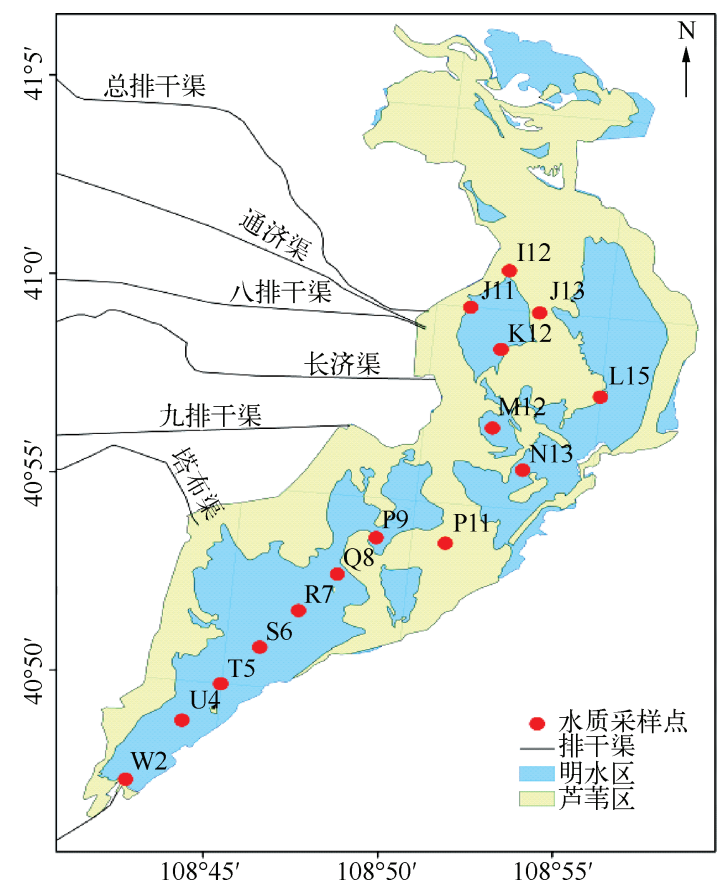

图 1 乌梁素海水体重金属采样点分布

Fig. 1 Location of different sampling sites of Lake Ulansuhai
乌梁素海 $\left(40^{\circ} 36^{\prime} \sim 41^{\circ} 03^{\prime} \mathrm{N}, 108^{\circ} 43^{\prime} \sim\right.$ $108^{\circ} 57^{\prime} \mathrm{E}$ ) 位于内蒙古自治区巴彦淖尔市乌拉特 前旗境内, 现有水域面积 $293 \mathrm{~km}^{2}$, 其中芦苇区面 积为 $118.97 \mathrm{~km}^{2}$, 明水区面积为 $111.13 \mathrm{~km}^{2}$, 明水 区中 $85.7 \mathrm{~km}^{2}$ 为沉水植物密集区. 湖水于每年 11 月初结冰, 翌年 3 月末到 4 月初开始融化, 冰封期 约为 5 个月. 气温变化较大, 湖区年平均温度 $7.3^{\circ} \mathrm{C}$, 全年日照时数为 $3185.5 \mathrm{~h}$, 多年平均降雨 量为 $224 \mathrm{~mm}$, 蒸发量为 $1502 \mathrm{~mm}^{[22-23]}$. 由于河套灌 区化肥和农药的用量在不断加大, 而化肥利用率 仅为 $30 \%$ 左右 ${ }^{[24]}$, 上游工业废水、生活污水伴随 大量流失化肥的农田排水经不同的排水沟进人乌 梁素海, 致使乌梁素海生态环境日益恶化.

\section{2 样品采集与测定}

根据我国水环境及湖泊湿地调查规范, 考虑 乌梁素海排污人湖口的分布及水动力学特征, 设 置样品采集点, 本次实验共设置 15 个水质采样点 (图 1). 采样时间为 2011 年 1 月, 采样点使用 GPS 定位, 由于采样时间为冬季, 湖面已结冰, 故 需要先将上层覆盖冰块通过冰柱采集器取出, 再 利用自行研制的多功能采水器采集水样 (专利 号:ZL201020680966. 1). 将水样盛放于用硝酸溶 
液洗涤的容量为 $1 \mathrm{~L}$ 的聚乙烯塑料取样瓶中. 放至事先备好的冰盒中, 使温度保持在 $-4 \sim 4^{\circ} \mathrm{C}$, 将样品送至 实验室进行重金属元素的分析测定. $\mathrm{Hg} 、 \mathrm{As}$ 采用双道一原子苂光光度计测定 ${ }^{[25]} . \mathrm{Cu} 、 \mathrm{Zn} 、 \mathrm{~Pb} 、 \mathrm{Cd} 、 \mathrm{Cr}$ 采用石墨 炉一原子吸收分光光度计进行测定 ${ }^{[26]}$. 为达到质量控制要求, 测试所用标准曲线相关性严格达标 $(r>$ $0.999)$, 同一样品分成 3 份作为平行样测定, 分析得到 $\mathrm{Cu} 、 \mathrm{Zn} 、 \mathrm{~Pb}$ 和 $\mathrm{Cr}$ 平行样的相对标准偏差 $(R S D)$ 分别 为 $1.8 \% 、 2.2 \% 、 1.6 \%$ 和 $0.7 \%$.

\section{3 统计分析}

1.3.1 单因子评价 现行《地表水环境质量标准》(GB/T 3838-2002) 中明确规定: “地表水环境质量评价应 根据应实现的水域功能类别,选取相应类别标准, 进行单因子评价”, 即与相应的标准进行比较, 进行污染 评估.

1.3.2 水环境健康风险评价模型 重金属污染物通过饮用水进人人体后,其引起的健康风险主要包括基因 毒性物质健康风险和躯干毒性物质 (非致癌物) 健康风险, 其中基因毒性物质可分为放射性污染物和化学致 癌物, 对于放射性污染物, 在一般水体中, 其污染程度很轻, 一般检测不出, 因此, 这里仅考虑化学致癌物质. 计算公式分别为 ${ }^{[27-28]}$ :

$$
\begin{gathered}
R_{\mathrm{c}}=\sum R_{\mathrm{c} i}=\sum\left[1-\exp \left(-D_{i} \cdot q_{i}\right)\right] / L \\
R_{\mathrm{n}}=\sum R_{\mathrm{n} i}=\sum 10^{-6}\left(D_{i \mathrm{~g}} / R f D_{i}\right) / L \\
D_{i \mathrm{~g}}=2.2 C_{i} / W
\end{gathered}
$$

式中, $R_{\mathrm{c} i}$ 为致癌物 $i$ (共 $k$ 种化学致癌物质) 经饮用水途径的平均致癌年险 $\left(\mathrm{a}^{-1}\right) ; R_{\mathrm{n} i}$ 为非致癌物 $i$ (共 $k$ 种化 学致癌物质) 经饮用水途径的平均健康风险 $\left(\mathrm{a}^{-1}\right) ; D_{i}$ 为化学致癌物 $i$ 经饮用水途径的单位体重日均暴露剂 量 $(\mathrm{mg} /(\mathrm{kg} \cdot \mathrm{d})) ; q_{i}$ 为化学致癌物 $i$ 的饮用水途径致癌强度系数 $(\mathrm{mg} /(\mathrm{kg} \cdot \mathrm{d})) ; R f D_{i}$ 为非致癌物质 $i$ 通过 饮用水途径摄人的参考剂量 $(\mathrm{mg} /(\mathrm{kg} \cdot \mathrm{d})) ; D_{i \mathrm{~g}}$ 为非致癌物质 $i$ 通过饮用水途径的单位质量日均暴露剂量 $(\mathrm{mg} /(\mathrm{kg} \cdot \mathrm{d})) ; 2.2$ 为成人每日平均饮水量 $(\mathrm{L}) ; C_{i}$ 为水体中各金属的实测浓度 $(\mathrm{mg} / \mathrm{L}) ; W$ 为人均体重 $(\mathrm{kg}) ; L$ 为人均寿命 $(\mathrm{a})$. 公式 (1) (3) 为水环境健康风险评价的基本模式. 对于不同研究区域的不同研究 对象,需要根据该地区的成人每日平均饮水量、人均体重以及人均寿命等因素变化来改进评价模型, 使得模 型适用于研究区域.

1.3.3 数据分析 采用 ArcGIS 9.3 的地统计模块对分析结果进行克里格空间插值. 并利用 Excel 和 SPSS 15.0 软件对数据进行处理和分析.

\section{2 结果与讨论}

\section{1 乌梁素海水环境特征分析}

乌梁素海位于中国北方寒旱区, 属于灌区草型湖泊, 是寒旱区典型气候条件和农牧交错区典型下垫面 条件下形成的湖泊,其湖泊水环境具有一定的特殊性. 本次采样季节是冬季, 湖泊水体冬季水温最低, 平均 值为 $0.32^{\circ} \mathrm{C}$, 最高值为 $0.50^{\circ} \mathrm{C}$, 最低值为 $0.10^{\circ} \mathrm{C}$, 过低的水温直接影响到微生物对污染物的降解作用, 致使 水体的自净能力大大下降; 水体 $\mathrm{pH}$ 值的均值为 8.18 , 其变异性较小, 最大值为 8.57 , 最小值为 7.67 , 说明乌 梁素海的水体为弱碱性. 乌梁素海湖泊水体氧化还原电位值随着季节变化而发生较大波动, 采样点水体氧 化还原电位平均值为 $83 \mathrm{mV}$, 最低值为 $-147 \mathrm{mV}$, 说明冬季湖泊水体处于强还原状态, 主要是由于乌梁素海 冰封期约为 $5 \sim 7$ 个月,湖泊表面冰盖的形成使得湖泊水体、沉积物与大气隔绝,处于厌氧环境,造成氧化还 原电位降低, 从而形成了强还原条件. 湖泊水体流速均值为 $0.018 \mathrm{~m} / \mathrm{s}$, 最大值为 $0.035 \mathrm{~m} / \mathrm{s}$, 最小值为 $0.004 \mathrm{~m} / \mathrm{s}$. 水体电导率均值为 $4.12 \mathrm{mS} / \mathrm{cm}$, 最大值为 $12.32 \mathrm{mS} / \mathrm{cm}$, 最小值为 $0.07 \mathrm{mS} / \mathrm{cm}$, 说明湖泊水体的 盐化程度较高.

\section{2 乌梁素海水体中重金属 $\mathrm{Hg}$ 的含量评估}

单因子指数评价法是将各指标浓度代表值与评价标准逐项对比, 以单项评价最差项目的类别作为水质 类别,是《地表水环境质量标准》( GB/T 3838-2002) 规定的评价方法.

乌梁素海表层水体中 $\mathrm{Hg}$ 含量范围在 $0.50 \sim 1.44 \mu \mathrm{g} / \mathrm{L}$ 之间, 平均含量为 $1.04 \mu \mathrm{g} / \mathrm{L}$, 其所有监测点的 
含量都超出地表水 III类标准 $(0.1 \mu \mathrm{g} / \mathrm{L})$ 和国家渔业用水标准 $(0.5 \mu \mathrm{g} / \mathrm{L}), 50 \%$ 的监测点超出了地表水 IV 类 标准 $(1 \mu \mathrm{g} / \mathrm{L})$. 以渔业用水标准作为评价标准, 利用单因子指数评价法对 $\mathrm{Hg}$ 含量进行评价, 其值在 $0.995 \sim$ 2.871 之间, 均值为 2.080 , 均大于 1 , 说明乌梁素海水体已受到 $\mathrm{Hg}$ 污染, 只能用于农业用水与景观用水. 其 水质对鱼类生存存在一定的风险, 在进行渔业养殖过程中需注意. 重金属的毒性系数揭示了金属对人体和 水生生态系统的危害 ${ }^{[29]}, \mathrm{Hg}$ 的毒性系数是 40 , 在所研究金属中属于毒性最大的金属, 因此要对 $\mathrm{Hg}$ 的危害 与危险程度予以重视.

\section{3 乌梁素海重金属 $\mathrm{Hg}$ 的空间分布特征}

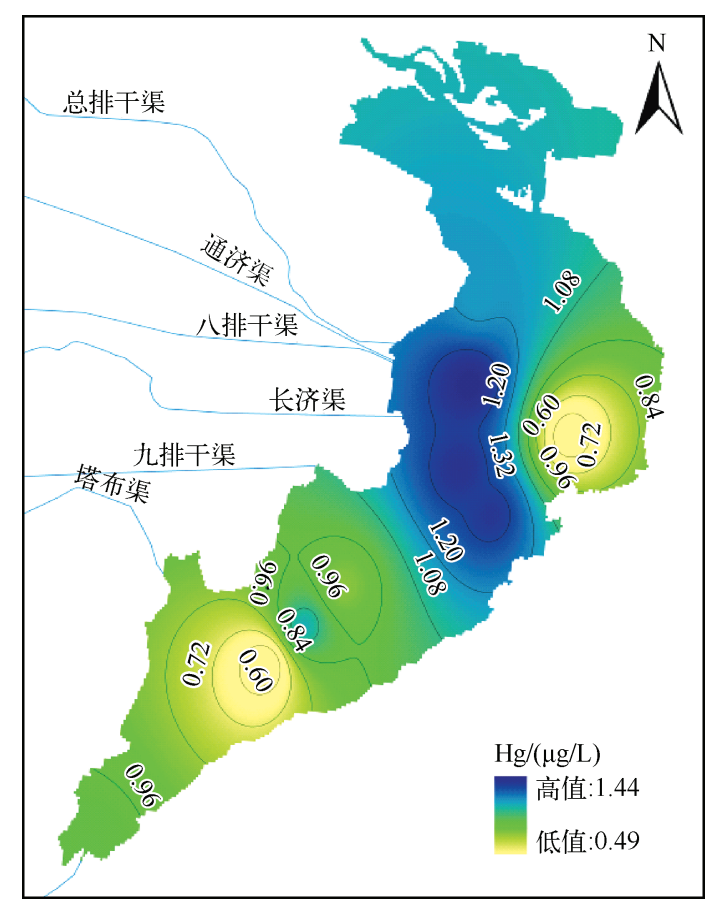

图 2 乌梁素海表层水中重金属采分布

Fig. 2 Heavy metal mercury distribution in surface water of Lake Ulansuhai
乌梁素海水体中 $\mathrm{Hg}$ 空间变异性较大, 为 $34.11 \%$, 说明其存在外在人为污染源的可能性更 大. 由于乌梁素海水体中 $\mathrm{Hg}$ 污染超标, 对其进行 空间分布特征分析, 可以更好地研究其污染特征.

$\mathrm{Hg}$ 的分布特征主要表现为:高值区域分布在 湖泊人水口集中的西北与东北部, 湖泊南部与出 口处的含量相对较低, 处于中等水平. $\mathrm{Hg}$ 含量在 $0.50 \sim 1.44 \mu \mathrm{g} / \mathrm{L}$ 之间, 平均浓度为 $1.04 \mu \mathrm{g} / \mathrm{L}$, 高 值点在 K12、M12 与 N13 监测点, 低值区在 L15 与 $\mathrm{R} 7$ 监测点 (图 2).

$\mathrm{Hg}$ 的空间分布特征是由一定的外界条件和 湖泊自身水环境差异造成的, 其受离排污口、湖水 人口的距离, 水动力条件, 水生植物分布等因素影 响. 此外, 由于取样季节为冬季, 湖泊水体重金属 的空间分布特征与沉积物中重金属的含量及沉积 物一水界面的环境因素有一定的关系, 因而不同的 重金属表现出不同的平面分布特征.

1) $\mathrm{Hg}$ 在湖泊人水口处的西北部含量较高,一 方面受径流输人与沿岸排污的影响. 虽然乌梁素 海冬季人湖水量相对较低, 且此季节乌梁素海的 补给水源主要为地下水、工业废水和生活污水, 但 从图 1 可以看出, 人水口的沿岸多为芦苇区, $\mathrm{Hg}$ 易 受有机物的吸附 ${ }^{[30]}$, 容易沉积于人口处, 不易向下 游传输与扩散. 此外, 重金属 $\mathrm{Hg}$ 从人水口进入湖

泊, 受到芦苇与藻类的吸附与拦截, 使得 $\mathrm{Hg}$ 被截留, 造成在湖泊人水口处的西北部出现高值区域.

2) 另一方面,在一些沉积物遭受严重污染的水体中, 沉积物的重新悬浮和释放成为水体 $\mathrm{Hg}$ 重要的输 入源 ${ }^{[31]}$. 由于冬季湖泊水体受冰盖的影响, 湖泊沉积物的重金属在外界环境发生变化后会发生重金属释放,造 成水体重金属浓度的差异. 冬季湖泊水体流速相对偏低, 湖泊水动力格局对浅水湖泊重金属含量具有控制作用. 水 体流速大、风速强的区域, 水动力作用相对较强, 表层沉积物与水体之间进行较为频繁的物质与能量交换, 使得 水环境中悬浮物难以沉降. 相反, 水流速度低, 水动力较弱, 水体中的重金属易于向沉积物中迁移 ${ }^{[32]}$. 乌梁素 海西北部的湖泊水体流速相对较高, 在 $0.020 \sim 0.035 \mathrm{~m} / \mathrm{s}$ 之间, 而湖泊南部的流速在 $0.004 \mathrm{~m} / \mathrm{s}$ 左右, 利用 湖泊水体流速表征湖泊水动力条件, 通过 SPSS 13.0 分析可知, 湖泊水体流速与 $\mathrm{Hg}$ 具有较好的相关性, 达到 了 0.01 置信水平以上, 相关系数分别为 0.756 . 这可以较好地说明, 湖泊水体流速对水体中 $\mathrm{Hg}$ 含量具有一 定的影响, 因此, 乌梁素海西北部湖泊沉积物中 $\mathrm{Hg}$ 相对释放量大于东南部, 造成其在湖泊人水口处的西北 部含量较高.

3) $\mathrm{Hg}$ 在天然水生生态系统中以多种形态存在, 如 $\mathrm{HgO} 、 \mathrm{Hg}^{2+} 、 \mathrm{Hg}(\mathrm{OH})_{n} 、 \mathrm{HgCl}_{n}$ 等. 游离 $\mathrm{Hg}^{2+}$ 只有在 $\mathrm{pH}<3.5$ 时才会存在. 一般在自然水体中, $\mathrm{Hg}^{2+}$ 会发生强水解反应 ${ }^{[33]}$, 但当含 $\mathrm{Hg}$ 的水溶液中存在 $\mathrm{Cl}^{-}$时, 必 
须考虑 $\mathrm{Hg}^{2+}$ 与 $\mathrm{Cl}^{-}$的络合平衡, $\mathrm{Hg}^{2+}$ 作为路易斯酸可与作为路易斯碱的 $\mathrm{Cl}^{-}$形成一系列络合物 $\mathrm{HgCl}_{n}^{2-n}$, 其 中 $n$ 为配位数 $(n=1 \sim 4)$, 由于有 $\mathrm{Cl}^{-}$存在生成较大量的 $\mathrm{Hg}-\mathrm{Cl}$ 络合物, 使此溶液中 $\mathrm{Hg}^{2+}$ 的溶解度增大 ${ }^{[34]}$. 乌梁素海水体盐化污染较为严重, 水体中 $\mathrm{Cl}^{-}$含量较高, 易形成 $\mathrm{HgCl}_{2}$ 和 $\mathrm{HgCl}_{3}^{-}$. 湖泊人水口处的西北部盐度 较高, 其 $\mathrm{Cl}^{-}$含量在 $1263 \sim 1646 \mathrm{mg} / \mathrm{L}$ 之间, 均值为 $1446 \mathrm{mg} / \mathrm{L}$, 而湖泊南部与出口处的 $\mathrm{Cl}^{-}$含量相对较低, 均值为 $81 \mathrm{mg} / \mathrm{L}$, 因此, 湖泊西北与东北部的 $\mathrm{Hg}$ 离子更易生成易溶于水的 $\mathrm{HgCl}_{n}$, 使得水体中的 $\mathrm{Hg}$ 含量 较高.

\section{4 乌梁素海水环境中 $\mathrm{Hg}$ 含量分析}

2.4.1 冰封期冰体与冰下水体中 $\mathrm{Hg}$ 含量分析 针对冬季水体进行分析, 冰封期水体受到太阳辐射和热交换 等诸多因素的影响后, $\mathrm{Hg}$ 污染特征将和非冰封期不同. 分别对冰体、冰下水体 $\mathrm{Hg}$ 含量进行测定,分析两者 之间的关系. 冰体中 $\mathrm{Hg}$ 含量在 $0.010 \sim 0.668 \mu \mathrm{g} / \mathrm{L}$ 之间, 平均值为 $0.187 \mu \mathrm{g} / \mathrm{L}$, 除 P9、R7 部分冰层中浓度 小于地表水环境质量 III 类标准 $(0.1 \mu \mathrm{g} / \mathrm{L})$ 外, 其它采样点 $\mathrm{Hg}$ 含量都远大于 $0.1 \mu \mathrm{g} / \mathrm{L}$, 结合乌梁素海水体 $\mathrm{Hg}$ 含量可知, 其在冰体和冰下水体中差距较大, 水体中 $\mathrm{Hg}$ 含量是冰体中含量的 $1.97 \sim 7.65$ 倍. 冬季重金属 $\mathrm{Hg}$ 含量相对较高, 研究冬季水体更能体现出其污染的危险性.

造成上述结果的原因主要是乌梁素海每年 11 月份随着冷空气过境、气温降低, 水温达到结冰点, 开始 产生结冰现象, 进入冻冰过程. 由于湖水在冻结过程中是从表层向下进行的, 且冰的微观结构不同于水的微 观结构, 在结冰的过程中, 污染物并不参与冰结构的构建, 即杂质不可能进人冰晶的内部, 因此在结冰过程 中杂质会自动排到冰层下面,在一定程度上起到净化的作用. $\mathrm{Hg}$ 作为冰体中的杂质,在其结冰的过程中会 不断地被排出. 当冰厚到一定程度, 冰封期水体的浓度会高于非冰封期水体的浓度, 而受到结冰速度、温度、 $\mathrm{Hg}$ 浓度等众多因素的影响,一部分 $\mathrm{Hg}$ 仍会残留在冰晶空隙之间.

伴随着温度的升高和季节的变化,进人非冰封期阶段,外界水环境条件发生改变,氧化还原性、酸碱度 等化学指标以及浓度梯度的变化也会影响 $\mathrm{Hg}$ 的迁移转化, 使得水体中 $\mathrm{Hg}$ 又重新分配到整个水体, 这样冻 融过程中的冰下水层相当于除底泥层之外的又一新污染内源. 因此,有必要在今后的研究中开展非冰封期 $\mathrm{Hg}$ 的环境化学特征研究.

2.4.2 冰封期冰下水体与沉积物中 $\mathrm{Hg}$ 含量分析 水在结冰过程中具有排出杂质的作用,冻结时冰层中污染 物的浓度降低, 冰下水体中污染物浓度随之升高, 促使冰下水体与沉积物发生进一步的物质交换. 伴随这一 过程, 冰一水一泥多介质环境特征都会发生相应的变化. 为了摸清水体与沉积物中 $\mathrm{Hg}$ 的相关关系, 在相关研 究中进行了沉积物中 $\mathrm{Hg}$ 含量测定, 发现冬季沉积物中 $\mathrm{Hg}$ 的最大值为 $0.34 \mathrm{mg} / \mathrm{kg}$, 最小值为 $0.06 \mathrm{mg} / \mathrm{kg}$, 均 值为 $0.16 \mathrm{mg} / \mathrm{kg}$, 其变异系数较大, 为 $57 \%$. 若变异系数大于 $50 \%$, 在一定程度上也表明其存在一定的人为 污染, 如人类活动等是其主要来源. $\mathrm{Hg}$ 在沉积物和水相中的循环和分布是物理、化学及生物作用, 从而可能 受诸如 $\mathrm{pH}$ 、温度、氧化还原变化、养分可用性及配位体等因素的影响. 冬季沉积物盐度较高, 其 $\mathrm{Cl}^{-}$含量较 高, 从而与水体中 $\mathrm{Hg}^{2+}$ 与 $\mathrm{Cl}^{-}$配合机理类似, 其沉积物中 $\mathrm{Hg}^{2}$ 易于与 $\mathrm{Cl}^{-}$相结合, 为了能够更明确地探求沉 积物中 $\mathrm{Hg}$ 的含量与湖泊沉积物盐度的关系, 用 SPSS 13.0 进行了相关性分析, $\mathrm{Cl}^{-}$的含量与 $\mathrm{Hg}$ 呈极显著正 相关, 全部达到 0.01 的置信水平, 相关系数为 -0.72 . 伴随着沉积物盐度的升高, 沉积物中 $\mathrm{Hg}$ 含量降低, 从 而使得水体中 $\mathrm{Hg}$ 含量升高, 这也说明冬季湖泊水体中 $\mathrm{Hg}$ 浓度升高, 一方面是由于水体结冰使得 $\mathrm{Hg}$ 不断地 被排人冰下水体,另一方面是因为冬季沉积物中的 $\mathrm{Hg}$ 也会在一定条件下释放到水体中.

\section{5 水体健康风险评估}

由于乌梁素海的水会汇人黄河, 因此基于乌梁素海的生态功能定位与重金属的危险性,对其水体中重 金属健康风险进行评估. 结合重金属含量评估结果,得知重金属 $\mathrm{Hg}$ 存在一定的污染, 为了便于比较重金属 $\mathrm{Hg}$ 对非致癌物质所产生健康风险的贡献, 将铜、锌、铅也进行了健康风险评估.

2.5.1 健康风险评价参数的选择 根据国际癌症研究机构 ( IARC) 和世界卫生组织 (WHO) 通过全面评价化 学物质致癌性可靠程度而编制分类系统, 躯体毒物质 (非致癌物质) 主要是 $\mathrm{Hg} 、 \mathrm{~Pb} 、 \mathrm{Cu} 、 \mathrm{Zn}$ 、氰化物、氨和酚, 本项目的研究中只涉及到 $\mathrm{Cu} 、 \mathrm{Zn} 、 \mathrm{~Pb} 、 \mathrm{Hg}$, 对于非致癌物质所致健康风险的评价, 参考剂量是一个重要的参 数. 根据有关资料, 查得非致癌物质 $\mathrm{Cu} 、 \mathrm{Zn} 、 \mathrm{~Pb} 、 \mathrm{Hg}$ 的饮水途径暴露的参考剂量分别为 $0.04 、 0.30 、 0.0035$ 和 $0.0003 \mathrm{mg} /(\mathrm{kg} \cdot \mathrm{d})^{[35]}$. 环境健康风险评价的对象为特定人群, 本次研究区域为内蒙古自治区. 根据中国卫 
生统计资料, 内蒙古自治区人均预期寿命为 $73.8 \mathrm{a}$,成人人均体重为 $65.0 \mathrm{~kg}^{[36]}$.

2.5 .2 健康危害的风险计算 根据健康风险评价模型和评价参数, 可以计算出 2011 年通过饮水途径, 非致 癌物质造成的平均个人年风险,计算结果见表 1 .

由表 1 可以看出, 总非致癌性污染物 ( Rn) 所致的健康危害风险度介于 $1.01 \times 10^{-9} \sim 2.49 \times 10^{-9} \mathrm{a}^{-1}$ 之 间, 即每年每千万人口中因饮用水中各类污染物而受到健康危害或死亡的人数不能超过 3 人. 从各非致癌 物元素对 $\mathrm{Rn}$ 的贡献率分析可知, 重金属 $\mathrm{Hg}$ 所致的健康危害风险度要远高于 $\mathrm{Cu} 、 \mathrm{Zn}$ 和 $\mathrm{Pb}$, 贡献率在 71. 43\% $92.44 \%$ 之间,重金属 $\mathrm{Hg}$ 的健康危害风险度在 $0.75 \times 10^{-9} \sim 2.15 \times 10^{-9} \mathrm{a}^{-1}$ 之间, 均值为 $1.56 \times 10^{-9} \mathrm{a}^{-1}$. 重金属 $\mathrm{Pb}$ 所致的健康危害风险度相对 $\mathrm{Hg}$ 较小, 贡献率在 $4.44 \% \sim 18.10 \%$ 之间, 健康危害风险度均值为 $0.143 \times 10^{-9} \mathrm{a}^{-1}$. 重金属 $\mathrm{Cu}$ 所致的健康危害风险度相对 $\mathrm{Hg} 、 \mathrm{~Pb}$ 较小, 贡献率在 $1.11 \% \sim 8.01 \%$ 之间, 健康 危害风险度均值为 $0.086 \times 10^{-9} \mathrm{a}^{-1}$. 重金属 $\mathrm{Zn}$ 所致的健康危害风险度最小, 贡献率在 $1.53 \% \sim$ $5.42 \%$ 之间, 健康危害风险度均值为 $0.04 \times 10^{-9} \mathrm{a}^{-1}$. 因此, 对非致癌性污染物所致的健康危害风险度由大 到小为 $\mathrm{Hg}>\mathrm{Pb}>\mathrm{Cu}>\mathrm{Zn}$. 因此, 应将重金属 $\mathrm{Hg}$ 作为首要的水环境健康风险管理控制指标.

表 1 乌梁素海非致癌性物质通过饮水途径产生的健康风险

Tab. 1 Health risk caused by noncarcinogens in water of Lake Ulansuhai

\begin{tabular}{|c|c|c|c|c|c|c|c|c|c|}
\hline \multirow{2}{*}{ 采样点 } & \multicolumn{5}{|c|}{ 健康风险 $/\left(\times 10^{-9} \mathrm{a}^{-1}\right)$} & \multicolumn{4}{|c|}{ 各非致癌物元素对 Rn 的贡献率/\% } \\
\hline & $\mathrm{Cu}$ & $\mathrm{Zn}$ & $\mathrm{Pb}$ & $\mathrm{Hg}$ & Rn & $\mathrm{Cu}$ & $\mathrm{Zn}$ & $\mathrm{Pb}$ & $\mathrm{Hg}$ \\
\hline $\mathrm{I} 12$ & 0.05 & 0.05 & 0.16 & 1.77 & 2.03 & 2.26 & 2.46 & 7.88 & 87.19 \\
\hline J11 & 0.04 & 0.06 & 0.14 & 1.55 & 1.79 & 2.23 & 3.35 & 7.82 & 86.59 \\
\hline $\mathrm{J} 13$ & 0.12 & 0.07 & 0.13 & 1.89 & 2.21 & 5.43 & 3.17 & 5.88 & 85.52 \\
\hline K12 & 0.17 & 0.05 & 0.12 & 2.15 & 2.49 & 6.96 & 1.93 & 4.82 & 86.35 \\
\hline L15 & 0.07 & 0.06 & 0.11 & 0.78 & 1.01 & 7.20 & 5.42 & 10.89 & 77.23 \\
\hline M12 & 0.03 & 0.04 & 0.10 & 2.08 & 2.25 & 1.51 & 1.56 & 4.44 & 92.44 \\
\hline N13 & 0.03 & 0.04 & 0.15 & 2.04 & 2.25 & 1.11 & 1.64 & 6.67 & 90.67 \\
\hline P9 & 0.11 & 0.03 & 0.11 & 1.29 & 1.54 & 6.95 & 1.88 & 7.14 & 83.77 \\
\hline P11 & 0.11 & 0.02 & 0.11 & 1.12 & 1.36 & 7.72 & 1.69 & 8.09 & 82.35 \\
\hline Q8 & 0.13 & 0.03 & 0.10 & 1.71 & 1.96 & 6.47 & 1.53 & 5.10 & 87.24 \\
\hline R7 & 0.08 & 0.03 & 0.19 & 0.75 & 1.05 & 8.01 & 2.86 & 18.10 & 71.43 \\
\hline S6 & 0.08 & 0.03 & 0.18 & 0.79 & 1.07 & 6.99 & 2.61 & 16.82 & 73.83 \\
\hline T5 & 0.06 & 0.03 & 0.17 & 0.89 & 1.14 & 5.42 & 2.27 & 14.91 & 78.07 \\
\hline $\mathrm{U} 4$ & 0.08 & 0.03 & 0.18 & 1.22 & 1.50 & 5.19 & 1.99 & 12.00 & 81.33 \\
\hline W2 & 0.13 & 0.03 & 0.20 & 1.47 & 1.83 & 7. 15 & 1.86 & 10.93 & 80.33 \\
\hline
\end{tabular}

\section{3 结论}

乌梁素海表层水体已受到重金属污染, 与地表水环境质量标准与渔业用水标准相比较, 重金属 $\mathrm{Hg}$ 的污 染较为严重,所有监测点 $\mathrm{Hg}$ 含量都超出地表水 III 类标准和国家渔业用水标准,50\% 的监测点超出了地表水 $\mathrm{IV}$ 类标准. 水体中重金属的 $\mathrm{Hg}$ 分布模式与离排污口距离、离湖水入口的距离和水动力条件有一定的关系, 高值区域分布在湖泊人水口集中的西北与东北部,湖泊南部与出口处的含量相对较低,处于中等水平. 重金 属 $\mathrm{Hg}$ 所致的健康危害风险度要远高于 $\mathrm{Cu} 、 \mathrm{Zn}$ 和 $\mathrm{Pb}$, 贡献率在 $71.43 \% \sim 92.44 \%$ 之间. 因此, 结合重金属含 量评估,应将重金属 $\mathrm{Hg}$ 作为首要的环境健康风险管理控制指标.

\section{4 参考文献}

[1] 侯亚敏,冯新斌,仇广乐等. 贵州百花湖表层水中不同形态录的分布规律. 湖泊科学,2004,16(2):125-134.

[ 2 ] Matida Y, Kumada H. Distribution of mercury in water, bottom mud and aquatic organisms of Mina Mata Bay, the River Agano and other water bodies in Japan. Bulletin of Freshwater Fisheries Research Laboratory, 1969,19(2) :73-93. 
[ 3 ] 李永华,王五一,杨林生等. 永的环境生物地球化学研究进展. 地理科学进展,2004,23(6):33-40.

[4] 丁振华,王文华,篗丽雅等. 贵州万山录矿区永的环境污染及对生态系统的影响. 环境科学,2004,25(2):111-114.

[ 5 ] 许 妍,陈永青. 我国环境录污染现状及其对健康的危害. 职业与健康,2012,28(7):879-881.

[ 6 ] 张军方,冯新斌,间海鱼.夜郎湖水库水体不同形态永的时空分布.生态学杂志,2011,30(5):969-975.

[ 7 ] 徐泽新,张 敏. 太湖流域湖荡湿地沉积物砷录的空间分布及污染评价. 长江流域资源与环境, 2013,22(5): 627-634.

[8] 萨茹莉,何 江,吕昌伟. 南海湖沉积物中 Hg 的形态分布特征. 沉积学报,2009,27(6):1178-1183.

[ 9 ] 刘 明,陈来国, 范瑞芳等. 鼎湖山大气气态总录含量和变化特征的初步研究. 环境科学学报, 2012,32(4): 932-939.

[10] 何天容,吴玉勇,冯新斌. 富营养化对贵州红枫湖水库永形态和分布特征的影响. 湖泊科学, 2010,22(2):208-214.

[11] 王 康, 康世昌, 郭军明等. 青藏高原纳木错流域水体总永的时空分布特征. 环境科学, 2012,33(7):2289-2296.

[12] 马冬梅,马 军,李 兴等. 内蒙古乌梁素海引排水量动态分析. 内蒙古水利,2012,(1):14-16.

[13］史小红,李畅游, 贾克力.乌梁素海污染现状及驱动因子分析. 环境科学与技术, 2007,30(4):37-40.

[14] 曹 杨, 尚士友,杨 景等.乌梁素海湿地时空动态演化. 地理科学进展,2010,29(3) :307-311.

［15］毛海芳,何 江,吕昌伟等.乌梁素海和岱海沉积物有机碳的形态特征. 环境科学,2011,32(3):658-666.

[16] 姜忠峰,李畅游, 张 生等. 改进 AHP 法在乌梁素海生态系统服务功能评价中的应用. 干旱区资源与环境,2011,25 (1) : 135-139.

[17] 王 爽,李畅游, 史小红等.乌梁素海沉积物中重金属形态分布特征及污染状况评价. 环境化学, 2012,31(10): 7-15.

[18］姜忠峰,张 生,李畅游等.乌梁素海表层沉积物重金属分布特征及生态风险评价. 环境工程学报,2012,6(6)： 1810-1816.

[19］刘俊廷,潘红捷,赵锁志等. 内蒙古乌梁素海底泥重金属元素污染评价. 地质与资源,2010,19(4):325-330.

[20］乌 云,朝伦巴根,李畅游等.乌梁素海表层沉积物营养元素及重金属空间分布特征. 干旱区资源与环境,2011,25 (4) : 143-148.

[21］付新峰,谷晓伟,刘晓岩等.乌梁素海生态功能定位初步分析. 人民黄河,2008,30(10):61-62.

[22] Ren CT, Li CY, Jia CJ et al. Water quality assessment for Ulansuhai Lake using fuzzy clustering and pattern recognition. Chinese Journal of Oceanology and Limnology,2008, 26 (3):339-344.

[23] Zhang Y, Li CY, Shi XH. The migration of total dissolved solids during natural freezing process in Ulansuhai Lake. Journal of Arid Land, 2012, 4(1) : 85-94

[24］贾红梅,李青丰,胡 杨等. 河套灌区总排干沟沿程及乌梁素海污染特征. 北方环境,2012,(4):72-79.

[25] 中国林业科学研究院分析中心. 现代实用仪器分析方法. 北京: 中国林业出版社,1993.

[26] 国家环境保护总局《水和废水监测分析方法》编委会. 水和废水监测分析方法:第 4 版. 北京: 中国环境科学出版 社,2002.

[27］耿福明,薛联青,陆桂华等. 饮用水源水质健康危害的风险度评价. 水利学报,2006,37(10):1242-1245.

[28] 万金保,闰伟伟,谢 婷等. 鄱阳湖流域乐安河重金属污染水平. 湖泊科学, 2007,19(4):421-427.

[29］樊文华,白中科,李慧峰等. 复垦土壤重金属污染潜在生态风险评价. 农业工程学报,2011,27 (1):348-354.

[30 ] Schluter K. Sorption of inorganic mercury and monomethyl mercury in an iron-humus podzol soil of southern Norway studied by batch experiments. Environmental Geology, 1997, 30(3/4):266-279.

[31］李宏伟,阎百兴,徐治国等. 松花江水中总录的时空分布研究. 环境科学学报,2006,26(5):840-845.

[32] 池俏俏,朱广伟,张战平等. 风浪扰动对太湖水体悬浮物重金属含量的影响. 湖泊科学,2006,18(5):495-498.

[33］孙嘉良.水体中录的转化与毒性.中小企业管理与科技,2009,(19):262.

[34] 杨士林,赵 哲,杨 红.水体中录的转化与毒性. 北方环境,2002,(1):33-34.

[35] 孙 超,陈振楼,张 翠等. 上海市主要饮用水源地地水重金属健康风险评价. 环境科学研究, 2009,22(1):60-65.

[36] 布仁巴图,孙 丽,潘兴强等. 江苏省与内蒙古自治区人均期望寿命对比分析. 中国初级卫生保健, 2009,23(4): $72-74$. 